\title{
Responses of Streamflow to Climate Change and Human Activities in a River Basin, Northeast China
}

\author{
Hanwen Zhang, ${ }^{1}$ Wei Xu, ${ }^{1}$ Xintong $\mathrm{Xu},{ }^{2}$ and Baohong $\mathrm{Lu}^{1}$ \\ ${ }^{1}$ College of Hydrology and Water Resources, Hohai University, Nanjing 210098, China \\ ${ }^{2}$ Jiangsu Rainfine Environmental Science and Technology Co., Ltd., Nanjing 210009, China \\ Correspondence should be addressed to Wei Xu; wei.xu.hhu@gmail.com
}

Received 16 September 2016; Accepted 11 June 2017; Published 30 July 2017

Academic Editor: Anthony R. Lupo

Copyright (c) 2017 Hanwen Zhang et al. This is an open access article distributed under the Creative Commons Attribution License, which permits unrestricted use, distribution, and reproduction in any medium, provided the original work is properly cited.

\begin{abstract}
It is now common knowledge that many water resources stresses relate to access to water within a basin. Yi River Basin, a typical river basin characterized by intensive agricultural processes, significant population growth, and water management, has been undergoing grave water problems. In this paper, the long-term trend of precipitation and streamflow in Yi River Basin, from 1964 to 2010, was investigated via Mann-Kendall test. The change point occurred in the year 1965 dividing the long-term series into two periods. Climate elasticity method and linear regression method were implemented to quantify the impact of precipitation and human activities on runoff and presented basically consistent results of the percentage change in an annual runoff for the postchange period. The results reveal that the decline of annual runoff in postchange period is mainly attributed to precipitation variability of $53.66-58.25 \%$ and human activities of $46.34-41.74 \%$, as estimated by climate elasticity method and linear regression method, respectively. This study detected the changes in the precipitation-streamflow relationship and investigated the possible causes in the Yi River, which will be helpful for providing a reference for the management of regional water resources.
\end{abstract}

\section{Introduction}

Streamflow, in terms of natural resource, is a measure of sustainable water availability, which is of great pith and moment for sustainable development, utilization of water resources, and biodiversity. With socioeconomic development, however, access to water has already become a serious issue for people in many parts of the world and, given recent United Nations estimates, the situation is not likely to improve $[1,2]$. Water-related problems, especially the variability and availability of regional water resources under influence of climate change and human activities, have been of great concern to hydrologists recently $[3,4]$. For sustainable water resources planning and management, it is therefore essential to determine the changes in water resources in both space and time and evaluate the influence of climate change and human activities thereon.

The streamflow of some rivers in the world has decreased significantly due to climate change and intensifying human activities [2, 5-7]. Milly et al. [5] investigated the observed trends of global streamflow and reported that runoff reduction occurred in sub-Saharan Africa, southern Europe, southernmost South America, Southern Australia, and western midlatitude North America, while the observed streamflow increases in the La Plate basin of southern South America, Southern through central North America, the Southeastern quadrant of Africa, and northern Australia.

China, whose water resources rank sixth in the world in terms of total volume though, suffers a lot from water shortage. To date, water stress in China remains a widely recognized concern of the general public [8]. The effects of climate variability and change, including increasing frequency of extreme events such as droughts, coupled with unevenly distributed water resources across regions and time, create additional pressure on the already scarce water supplies. Zhang et al. [9] investigated the trends of annual streamflow in the six large basins in China based on the observed runoff data of 19 main hydrological stations for the past 50 years and concluded that the annual streamflow of all investigated basins shows a downward trend, with some presenting 
significant decreasing trend in the northern China. Piao et al. [10] reviewed runoff changes in the Yangtze River Basin and Yellow River Basin, two largest basins in China, and reported a small and statistically insignificant upward trend detected in in annual runoff of Yangtze River Basin since 1960, while the Yellow River Basin showed a persistent decline in annual runoff time series. Zhang et al. [4] also found similar changing patterns based on monthly streamflow data from 382 hydrological stations in China covering the period 1960-2000. They reported that declining streamflow was found in the northern China and the upper reaches of the Yangtze and the Pearl River Basins, and significant decreasing streamflow was found mainly in the Yellow River Basin, the Liaohe River Basin, and the Haihe River Basin.

It is common knowledge that the planning, designing, and operating of water resources projects are generally based on observational and historical hydroclimatologic data. The underlying assumption of this idea is that time-invariant statistical characteristics of the considered time series in all water resources engineering work, which would inevitably trigger major problems in regional water resources management [11]. Hence, it has been an important scientific problem in hydrology to reveal the physical characteristics of the basin and trends of streamflow change and their influencing factors. Moreover, the hydrologic cycle at the watershed scale is a complex process affected by climate, intensifying human activities and so on $[12,13]$; thus the impacts of precipitation and human activities generally vary from place to place and need to be investigated at local scale to better understand the consequences of human activities and serve water resources planning, management, and sustainable development in that region.

Yi River, tributary of Huaihe River system, has experienced grave water problems in recent years, such as, as reported by Zhang et al. [14], flooding, water shortage, high regulation, serious pollution, and aquatic ecology degradation. Water resources have become one of the key constraints of local socioeconomic development. Yet, research on the streamflow of Yi River Basin is rarely reported. In the light of these facts, this paper attempts to assess the half-centurylong changing characteristics of precipitation and streamflow of Yi River to quantify the impacts of climate change and human activities on hydrological process of Yi River, aiming to better understand the changes in precipitation-streamflow in Yi River and how the runoff responds to climate change and anthropological activities, which is of great pith and moment for rational utilization and management of water resources and the local ecological protection.

\section{Materials and Methods}

2.1. Study Area and Data Set. Yi River Basin, extending from longitude $117^{\circ} 24^{\prime} \mathrm{E}$ to $119^{\circ} 11^{\prime} \mathrm{E}$ and latitude $34^{\circ} 22^{\prime} \mathrm{N}$ to $36^{\circ} 23^{\prime} \mathrm{N}$, is located in southeast of Shandong Province, China (Figure 1). Originating from Yimeng Mountain, Yi River flows through Shandong Province and extends south to Jiangsu Province, with a total length of $333 \mathrm{~km}$ and a drainage area of $11,820 \mathrm{~km}^{2}$.
The hilly area lies in the middle and north part of Yi River Watershed and accounts for $70 \%$ of total basin area, leaving the rest mainly the plain area. The climate is characterized by north temperate monsoon, with average annual mean temperature of $13.2^{\circ} \mathrm{C}$ and average annual precipitation $830 \mathrm{~mm}$. The flood season normally occurs in June to September, and the amount of precipitation in this period accounts for about $74.2 \%$ of annual total precipitation, while the main flood season, July to August, produces the highest flooding. Due to the mountainous nature, the floods in Yi River feature high peaks, large volume, and flash floods. Affected by the changes in rainfall distribution and topography, Yi River lacks water in dry season, while being frequented with flash floods in wet season, causing difficulties in the development and utilization of water resources.

Linyi hydrological station, outlet of Yi River Basin, is selected to investigate the annual and monthly runoff variation. Streamflow data was obtained from the Hydrologic Yearbook, spanning 57 years (1954-2010), in conjunction with daily precipitation records of seven meteorological stations covering the same period were acquired from National Meteorological Information Center, China Meteorological Administration (http://data.cma.cn/site/index.html) (Figure 1). The mean annual precipitation data for the river basin in the investigated time frame were interpolated by the Kriging method using ArcGIS with annual precipitation data of the meteorological stations in the river basin.

2.2. Methods. Quantifying the respective contributions of natural factors and human activities to streamflow changes is important not only in theoretical perspective, but also in water resources management and soil and water conservation measures. However, it is never an easy and straightforward process; many methods have been developed to investigate the impacts of climate change and human activities quantitatively in the literature; the selection of the "best" method to be employed in such quantitative evaluation remains an open and debated question. For instance, Saifullah et al. [7] simply emphasized this fact by saying that "...several methods have been used to assess the impacts of precipitation and land surface changes on the hydrological processes, but to date, no standard model has been developed...." In terms of the methods, two categories can be identified, that is, hydrological modelling and statistical modelling. With reference to the first category, paired catchment experiment method and physically based hydrological model (lumped or distributed), such as Xinanjiang Model, Soil and Water Assessment Tool (SWAT), Variable Infiltration Capacity Model (VIC), SIMHYD Model, HBV Model, the SLURP (Semidistributed Land Use-Based Runoff Processes) Model, were at the top of list for determining the impact of climate change and human activities on the hydrological process (e.g., [15-20]). However, the experimental methods are usually time-consuming, expensive, and difficult to locate suitable controls. The physically based hydrological models, though physically sound, are also limited because of the involvement of major efforts on model calibration and validation, high demand of various data (e.g., high-resolution land use data, soil data, and groundwater data) to represent the 


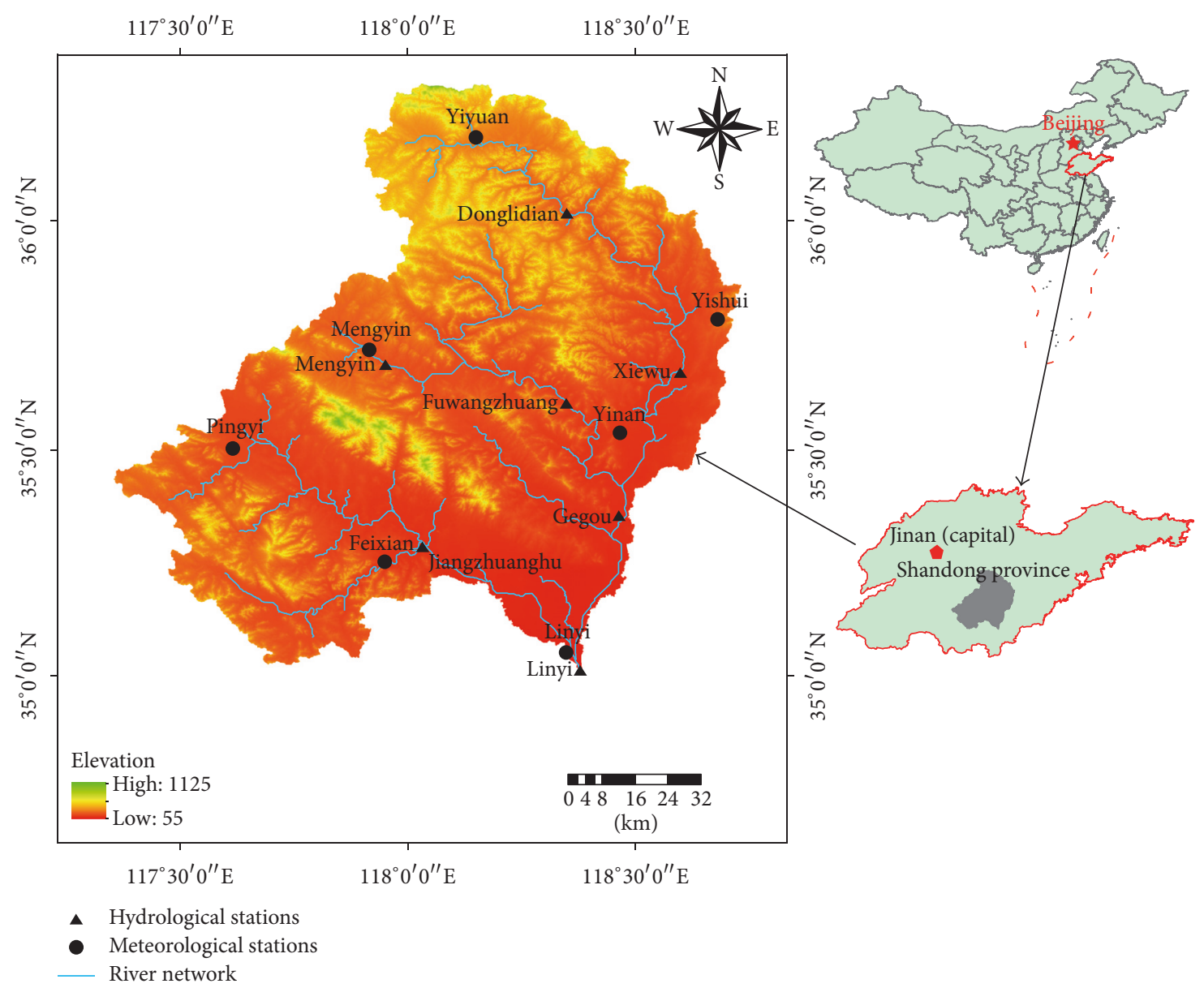

FIGURE 1: Sketch map of study area, hydrological and meteorological stations.

hydrophysical processes, and the entanglement of complexity and uncertainty in model structure and parameter estimation $[15,17,21,22]$. Statistical approach provides alternative choice, for instance, regression analysis method [23, 24], hydrological sensitivity analysis method (see, among others, [17, 22, 2529]), and elasticity method [30, 31]. Nonetheless, climate elasticity method, for instance, has its limitations too; the general framework used to estimate proportional contribution of climate and human impact on streamflow is based on the assumption that human activities are independent of climate change. As a matter of fact, human activities and the climate system interact with each other. At a catchment scale, climate change may play a dominant role in land use and land cover change (LUCC) and may consequently alter the amount and process of streamflow.

It is therefore varying from case to case to choose the appropriate methods to estimate the response of streamflow to climate change and human activities quantitatively. Ideally, implement of a combination of both approaches should compensate for other to some extent. Due to limited access to soil and groundwater data to perform a hydrological model, this paper employs statistical approach.

2.2.1. Trend and Abrupt Change Point Detection. The rankbased MK test [32-34] is a parameter-free trend detection technique within time series. Due to its power and advantages, such as high asymptotic efficiency, it is frequently used in the literature (e.g., [35-38]). Also, different variants can be found in MK test [39]. In this study, the method examined by Moraes et al. [40] and Gerstengarbe and Werner [41] is adopted, which can be briefly outlined as follows.

Given a time series $x_{i}$ with $n$ terms $(1 \leq i \leq n)$, the MK rank statistic $a_{k}$ is given as

$$
a_{k}=\sum_{i=1}^{k} R_{i}
$$

where

$$
R_{i}= \begin{cases}+1, & x_{i}>x_{j} \\ 0, & x_{i} \leq x_{j}\end{cases}
$$

Under the null hypothesis $H_{0}$ of no change, the statistic $a_{k}$ is normally distributed with mean and variance given by

$$
\begin{aligned}
E\left(a_{k}\right) & =\frac{n(n-1)}{4}, \\
\operatorname{var}\left(a_{k}\right) & =\frac{n(n-1)(2 n+5)}{72} .
\end{aligned}
$$


As such, the definition of the statistic index $u\left(a_{k}\right)$ is calculated using following:

$$
u\left(a_{k}\right)=\frac{\left(\left(a_{k}-E\left(a_{k}\right)\right)\right)}{\left(\operatorname{var}\left(a_{k}\right)\right)^{1 / 2}} \quad k=1,2,3, \ldots, n .
$$

$u\left(a_{k}\right)$ is distributed as a normal distribution (it is named here $U F$, as it is calculated forwardly according to the order $\left.x_{1}, x_{2}, x_{3}, \ldots, x_{n}\right)$. A positive $U F$ value denotes an increasing trend, and a negative $U F$ value denotes a decreasing trend. Given the significance level of $\alpha$, the null hypothesis is rejected if $|U F|>U_{\alpha / 2}$ (two-sided statistical test), indicating that there is an obvious (or significant) trend change in the $x$ time series. Then the statistic index of the corresponding rank series for retrograde rows, $U B$ (as it is computed backwardly for the reverser sample, $\left.x_{n}, x_{n-1}, x_{n-2}, \ldots, x_{1}\right)$, are similarly obtained through the method mentioned above.

Also, let $U B=-U F$ denote the trend of retrograde time series. Then the two curves, $U F$ and $U B(k=1,2,3, \ldots, n)$, are plotted to localize the beginning of the change, at the intersection point between the curves. If the intersection point is significant at given significance level, the match point would be the break point occurring in the investigated time series at that time. The considered $\alpha$ is 0.05 in this study, and the corresponding $U_{\alpha / 2}$ is 1.96 .

\subsubsection{Quantifying the Impact of Climate Change and Human} Activities on Runoff. Changes of the observed mean annual streamflow $\Delta \bar{Q}_{\text {total }}$ are subject to climate variability (represented by precipitation, $\Delta \bar{Q}_{P}$ ) and human activities $\Delta \bar{Q}_{h}$.

$$
\Delta \bar{Q}_{\text {total }}=\Delta \bar{Q}_{P}+\Delta \bar{Q}_{h} .
$$

To evaluate the impacts of precipitation and human activities, respectively, the investigated time frame was divided into two periods through trend and abrupt change point analysis, that is, prechange period and postchange period. As such, a change in the average annual streamflow is calculated as

$$
\Delta \bar{Q}=\Delta \bar{Q}_{2}-\Delta \bar{Q}_{1},
$$

where $\Delta \bar{Q}$ denotes the change in annual mean runoff, $\Delta \bar{Q}_{1}$ and $\Delta \bar{Q}_{2}$ represent annual runoff during prechange period and postchange period, respectively.

Simple Linear Regression Method. Take prechange period as unimpaired reference period, where a regression equation can be obtained between annual streamflow $\left(Q_{1}\right)$ and averaged annual precipitation $\left(P_{1}\right)$ of the basin as follows:

$$
Q_{1}=a P_{1}+b,
$$

where $a$ and $b$ are two parameters of the model.

Then the streamflow without the influence of human activities in the change period can be modelled as

$$
\bar{Q}_{2}^{\prime}=a \bar{P}_{2}+b,
$$

where $\bar{Q}_{2}^{\prime}$ and $\bar{P}_{2}$ are fitted mean streamflow and observed precipitation during the change period, respectively.

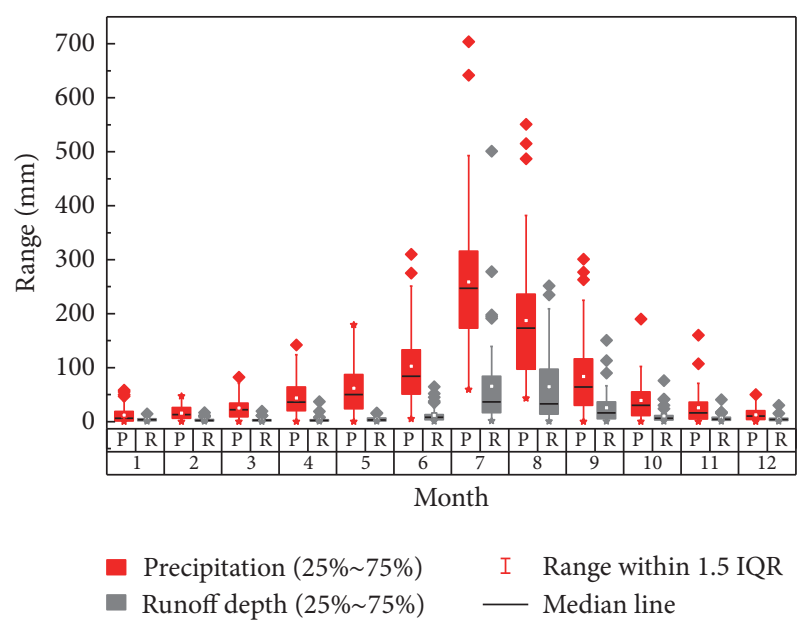

FIGURE 2: Long-term monthly average precipitation and runoff depth of the Yi River Basin.

The contribution of runoff changes by human activities and precipitation can be estimated as

$$
\begin{aligned}
& \Delta Q_{h}=\bar{Q}_{2}-\bar{Q}_{2}^{\prime}, \\
& \Delta Q_{P}=\Delta \bar{Q}-\Delta Q_{h} .
\end{aligned}
$$

Climate Elasticity Method. Climate elasticity of streamflow developed by Schaake and Waggoner [30] is considered to be an important, efficient, and robust indicator assessing the sensitivity of streamflow to climate change [20,31, 42]. The climate elasticity can be estimated in different ways, and the nonparametric estimator proposed by Zheng et al. [31] was employed in this paper. The elasticity of streamflow with respect to precipitation $\left(\varepsilon_{P}\right)$ can be expressed as follows:

$$
\varepsilon_{P}=\frac{\bar{P}}{\bar{Q}}=\frac{\sum\left(P_{i}-\bar{P}\right)\left(Q_{i}-\bar{Q}\right)}{\sum\left(P_{i}-\bar{P}\right)^{2}}=\rho_{P, Q} \cdot \frac{C_{Q}}{C_{P}},
$$

where $\rho_{P, Q}$ is the correlation coefficient of precipitation $(P)$ and streamflow $(Q)$ and $C_{P}$ and $C_{Q}$ are coefficients of variation of $P$ and $Q$.

\section{Results and Discussions}

3.1. Change Points Analysis. In the Yi River Basin, precipitation mainly occurs during June-September. November, December, January, and February are the dry months, as is the case of runoff experienced (Figure 2). Compared with dry months, there seems to be more outliers in wet months. With reference to average monthly precipitation, the highest value occurred in July, while the least occurred in January; regarding average monthly runoff, the highest value occurred in July, while the least occurred in March, illustrating that high flow responds to high precipitation simultaneously, while low flow responds with apparent delay in time.

Before further trend detection analysis, serial persistence within the meteor-hydrological series was performed 
TABLE 1: MK test result of annual precipitation and streamflow during 1954-2010.

\begin{tabular}{lcc}
\hline Time series & MK value & Trend \\
\hline Precipitation & -2.1 & Downward \\
Streamflow & -0.7 & Downward \\
\hline
\end{tabular}

Note. ${ }^{*}$ denotes significant at $5 \%$ significance level.

(Figure 3). It can be seen from Figure 3 that the series include independent observations both for annual streamflow series and for annual precipitation series at 95\% confidence level. This result announces that the application of MK trend detection technique is warranted in this study.

The trend analysis results were presented in Figure 4 and Table 1. Note that a negative UF value denotes a downward trend and vice versa, and if the $U F$ value is greater than the critical values $( \pm 1.96$, two dashed lines in Figure 4$)$, then the increasing or decreasing trend is significant at $5 \%$ significance level. Figure 4 showed that both the annual precipitation and streamflow decreased in Yi River Basin during 1954-2010 and the significant decreasing trend was found in streamflow. MK value of precipitation fluctuated between positive and negative value during 1965-1975, while the UF value of streamflow was negative from 1967 to 1975, indicating that the decrease of runoff may be attributed to anthropological impacts.

Though multiple intersection points of precipitation were identified and none was significant at 5\% significance level, the precipitation generally presented a downward trend since 1965 , only differed in decreasing degrees. Figure 5 presented the variations of precipitation and streamflow before and after 1965. The mean annual precipitation decreased by $153 \mathrm{~mm}$ from pre-1965 period to post-1965 period, while the average annual runoff depth decreased by $231.1 \mathrm{~mm}$ from pre-1965 period to post-1965 period, indicating that the process of the runoff production may have changed.

To better understand the change characteristics in precipitation, the double mass curve [43] was employed. The annual precipitation-runoff double mass curve is normally approximate to a straight line if the basin characteristics are stable; that is, there are no abrupt changes in precipitation and runoff; thus, a change in the slope of the curve may indicate a change in the investigated series. The double mass curve of precipitation-runoff was represented in Figure 6. It can be seen from Figure 6 that the slope of lines of the pre-1965period is more than twice higher than a post-1965-period. The maximum value of runoff coefficient is 0.58 for the period of 1954-1964. After 1965, runoff coefficient abruptly decreases, and the mean runoff coefficient of pre-1965-period is 0.40 , while that of post-1965-period is 0.18 (Table 2), which is evidence of the change point.

Comparing the results of the change point test and double mass curve, the year 1965 could be the change point representing the impact of precipitation and human activities on runoff. Figure 7 shows a correlation comparison of precipitation and runoff for the two periods. The correlation between precipitation and streamflow for the prechange
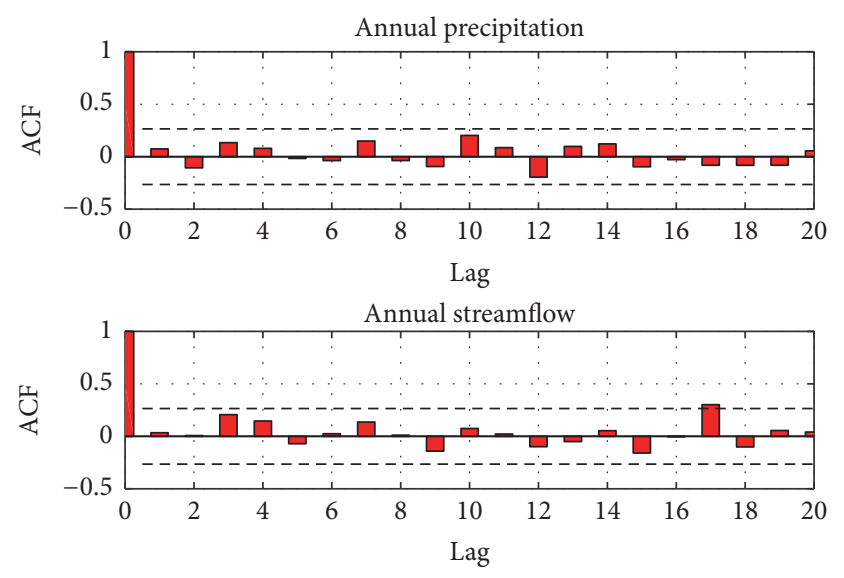

FIgURE 3: Autocorrelation analysis of meteor-hydrological series of the Yi River Basin. The dashed lines denote 95\% confidence level (ACF means autocorrelation functions).

period $(r=0.89)$ is slightly stronger than that for postchange period $(r=0.86)$, while the slope decreased from 0.79 to 0.55 . The lower standard deviation of runoff (Table 2) confirms that change of runoff tends to stabilize, arrantly under the influence of anthropological activities. The decrease of slope from prechange period to postchange period also demonstrates that the same annual precipitation in the baseline period produces more streamflow, suggesting that streamflow should be driven by increasing human activities in the study area. According to the records of Hydrologic Year-book, there are 5 large sized reservoirs and 22 medium sized reservoirs, whose total storage volumes range from $9.5 \times 10^{6}$ to $7.49 \times$ $10^{8} \mathrm{~m}^{3}$ (due to the size of the paper, only part of the reservoirs are listed in Table 3). It can be seen that most of the reservoirs were built during the 1960s and 1970s; hence, water-related human activities including agricultural irrigation, dam construction and industry development should be considered to be responsible for the decline in runoff.

As per the discussion above, it can be concluded that runoff should be affected by the anthropological impacts in this region after 1964.

\subsection{Quantitative Assessment of Precipitation and Human} Activities on Streamflow. The precipitation elasticity of runoff was estimated by (10) to assess the impact of precipitation change on runoff. The value of $\varepsilon_{P}$ is 1.95 , indicating that a $10 \%$ decrease in precipitation should result in $19.5 \%$ decrease in runoff. According to the equation, with the calculated $\varepsilon_{P}$, it can be calculated that the $153.04 \mathrm{~mm}$ decrease in precipitation during 1965-2010 may led to a $123.99 \mathrm{~mm}$ decrease in streamflow, accounting for $53.66 \%$ of the total observed drop in annual runoff. The climate elasticity method measures climate influence on streamflow and assumes that the remaining change would come from human influence such as LUCC. Therefore, human activities could contribute $46.34 \%$ of the decrease in streamflow.

With regard to the simple linear regression method, the difference of simulated runoff after the change point is 


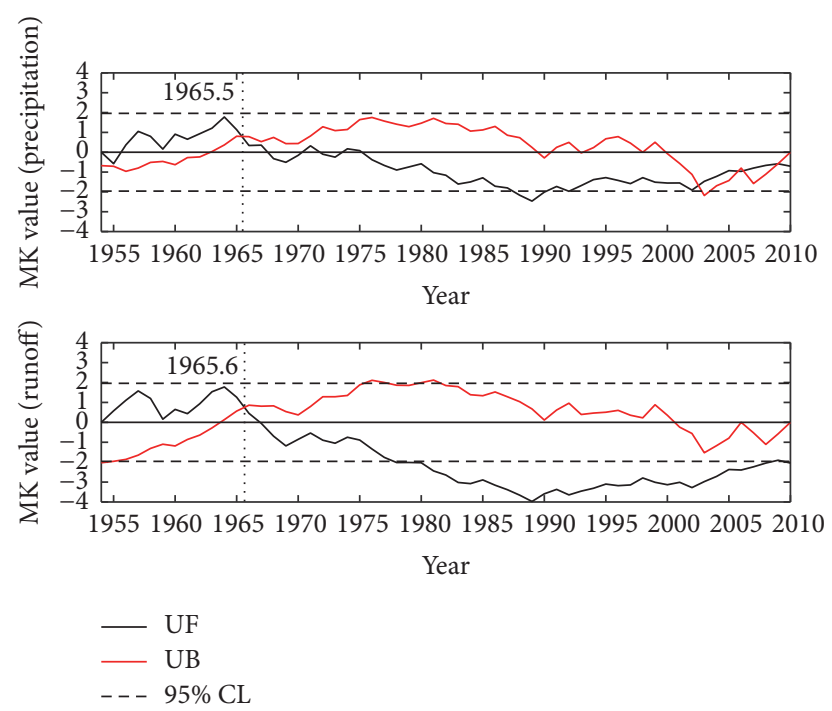

FIGURE 4: MK test of meteor-hydrological series of the Yi River Basin. The dashed lines denote $95 \%$ confidence level.
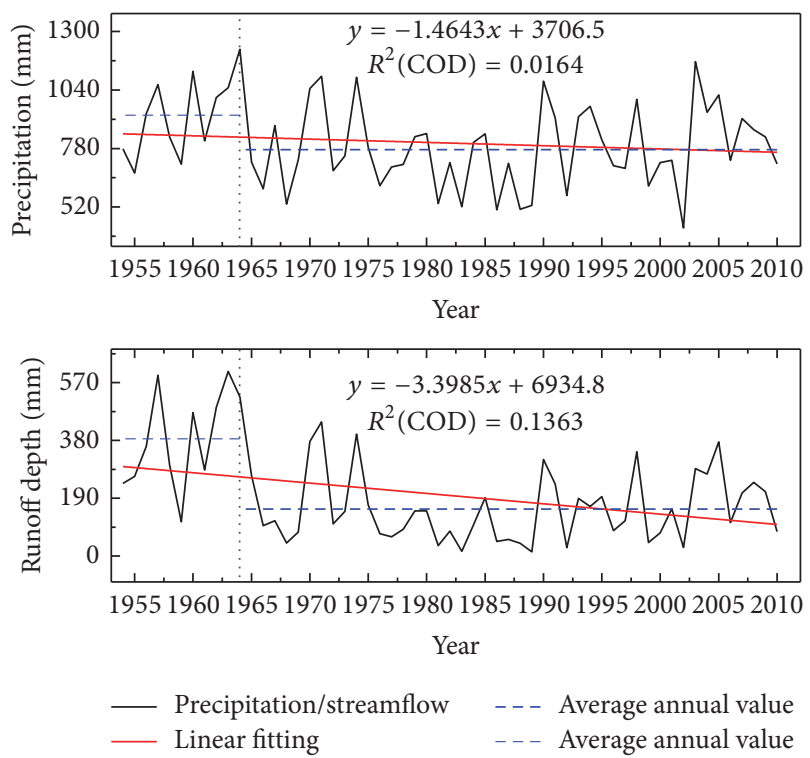

FIgURE 5: Time series of annual precipitation and runoff depth in Yi River Basin (the thin dashed blue line denotes average value before 1965; the thick dashed blue line denotes average value from 1965 to 2010).

assessed for the impact of precipitation change. Stimulated annual mean runoff in the study area during 1965-2010 is $250.83 \mathrm{~mm}$; hence, human activities may have resulted in $96.43 \mathrm{~mm}$ decrease of annual runoff, estimating $41.74 \%$ of the runoff reduction, while the rest $(58.26 \%)$ was attributed to climate change.

3.3. Discussions. In the present work, two statistical methods were selected to quantify the response of streamflow to climate change and human activities in Yi River Basin due to limited access to soil and groundwater data to perform

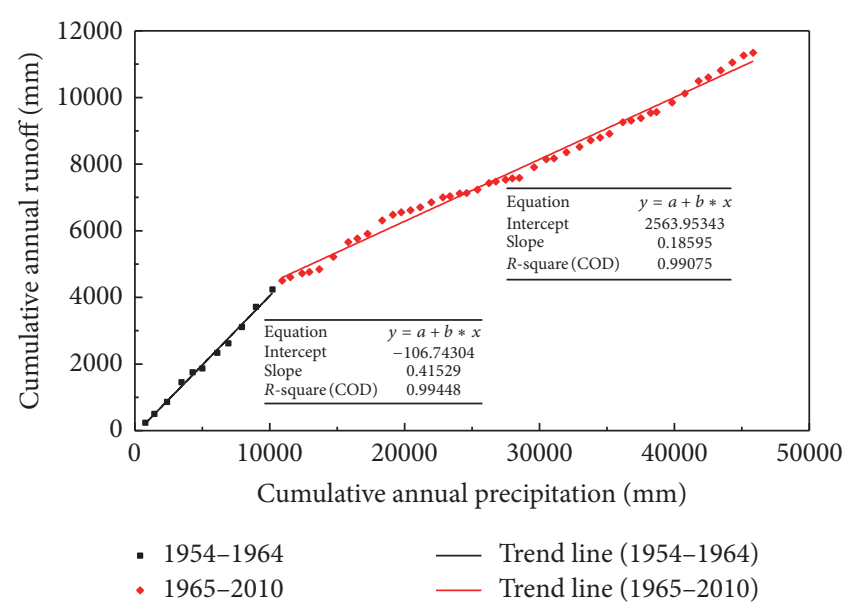

FIGURE 6: Double mass curve of precipitation and runoff depth.

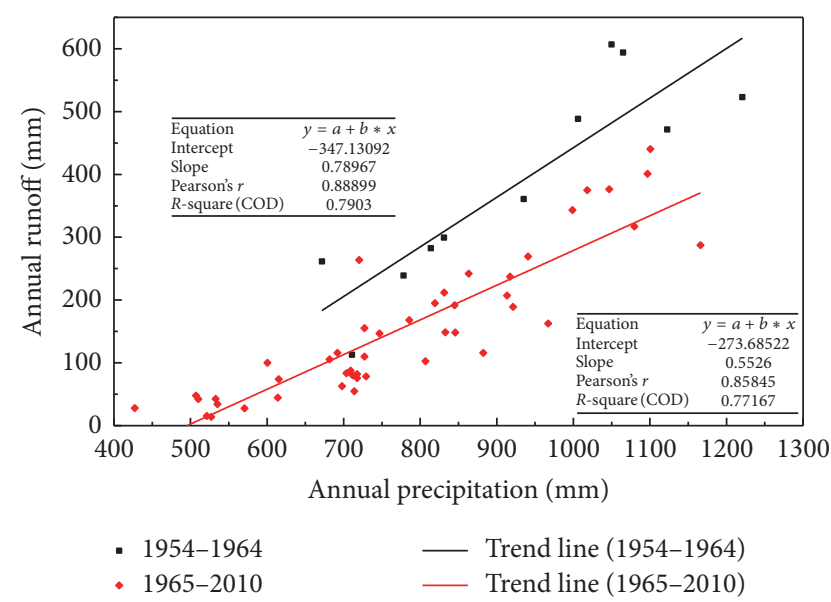

FIGURE 7: Correlation analysis of precipitation and runoff for pre/postchange period.

a hydrological model. It can be seen that both methods are generally easy to satisfy the data requirement and easy to be implemented. However, as Legesse et al. [44] pointed out, physically based hydrological models may be preferred and even the most optimal choice for hydrological effect study, though, as stated previously, limitations still remain in practice for them to be applied at basin scale. The statistical approach, on the other hand, only requires basic meteorological data such as precipitation and normal hydrological data, such as runoff series. In particular, climate elasticity method needs less and climate elasticity parameter can be directly estimated by hydroclimatic data without parameter adjustment per nonparametric estimators. Compared with parametric estimators of climate elasticity, nonparametric estimator for $\varepsilon_{P}$ has been determined to be robust, appropriate with smaller bias, and consistent with the results estimated using rainfall-runoff model $[42,45]$. In the present study only precipitation elasticity was investigated as streamflow responds directly to precipitation. But, it is clear-cut that the climate elasticity method is not expected to provide enough 
TABLE 2: Summary of annual precipitation, streamflow, and runoff coefficient during 1954-2010.

\begin{tabular}{|c|c|c|c|}
\hline Period & $\begin{array}{l}\text { Prechange } \\
1954-1964\end{array}$ & $\begin{array}{c}\text { Postchange } \\
1965-2010\end{array}$ & $\begin{array}{c}\text { Full time frame } \\
1954-2010\end{array}$ \\
\hline \multicolumn{4}{|l|}{ Precipitation } \\
\hline Mean (mm) & 927.70 & 774.66 & 804.20 \\
\hline Standard deviation & 179.12 & 181.76 & 189.71 \\
\hline Coefficient of variation & 0.19 & 0.23 & 0.24 \\
\hline \multicolumn{4}{|l|}{ Streamflow } \\
\hline Mean (mm) & 385.45 & 154.39 & 198.98 \\
\hline Standard deviation & 161.02 & 112.98 & 152.81 \\
\hline Coefficient of variation & 0.42 & 0.73 & 0.77 \\
\hline Runoff coefficient & 0.40 & 0.18 & 0.22 \\
\hline
\end{tabular}

TABLE 3: Summary of large and medium sized reservoirs in Yi River Basin.

\begin{tabular}{lccc}
\hline Reservoir names & Size & Build date & Total storage $\left(10^{4} \mathrm{~m}^{3}\right)$ \\
\hline Tianzhuang & Large & 1960 & 13057 \\
Dian & Large & 1960 & 74900 \\
Bashan & Large & 1960 & 50850 \\
Xujiaya & Large & 1959 & 29290 \\
Tangcun & Large & 1959 & 14961 \\
Gaohu & Medium & 1967 & 3741 \\
Shangye & Medium & 1960 & 3638 \\
Cangli & Medium & 1971 & 6480 \\
Wujiazhuang & Medium & 1960 & 2544 \\
Shilan & Medium & 1960 & 3682 \\
\hline
\end{tabular}

information compared with physically based distributed model.

It is also relevant to note that there are uncertainties associated with assessing effects of climate variability and human activities on runoff in both methods, even though the evaluated effects are relatively consistent. The first source of uncertainty lies in the fact that both methods are only for the effect of the changes in runoff with changes in mean annual precipitation. While in real world, streamflow can be influenced by variations in other precipitation characteristics, such as seasonality, intensity, and concentration. Additionally, occurrence of extreme runoff may also affect the accuracy. The second comes from the framework to separate the effect. Regarding simple linear regression method, the hydroclimatic data may be lacks of representation if a short baseline period is detected in the change point analysis. What the regression model actually conveys is the response of hydrologic process to the average climatic conditions in the baseline period. The relationship estimated as per the date in a wet baseline period would greatly differ with that in a dry baseline period. Furthermore, the relationship between the precipitation and runoff may have changed in a nonstationary environment. As climate elasticity method, the framework used to estimate proportional contribution of climate variability and human activities to runoff is based on the assumption that human factors are independent of climate factors. The effects of human activities and climate, in fact, interplay with each other and are not readily separable. At a basin scale, climate change may influence the human activities such as land use and thus change runoff consequently, and vice versa, intensifying urbanization and expanding population may cause increase in temperature and consequently result in change in hydrological regime. Despite the fact that human activities and climate system interact with each other, even in baseline period, it is not considered as such in the present study. Therefore, focus of further studies should be placed in future to improve the results of separating climate and anthropogenic effects with consideration of these uncertainties.

\section{Conclusions}

Global and regional climate variability is regarded as an important factor affecting hydrological processes. Concurrently, development-induced human activities have been identified as a main factor causing runoff variation in Yi River Basin. It is hence useful to update the understanding of the changes in precipitation-streamflow in Yi River and to separate the effects of climate variability from that of human activities. In this study, two different approaches, that is, simple 
linear regression method and climate elasticity method, have been used to investigate the impacts of the precipitation and land surface changes on runoff. The variation characteristics of annual precipitation and runoff, during 1954-2010, were analyzed. Downward trend was found for both precipitation and runoff using MK test. Streamflow series in the study area presented greater decline and is statistically significant (5\% level), compared with the precipitation time series. A beak point in runoff was identified in 1965; also, similar result was found in precipitation series. Though multiple intersection points were found in precipitation series, the break point 1965 could be the change point representing the impact of precipitation and human activities on runoff considering the results of the change point test and double mass curve.

Compared with linear regression method, the climate elasticity method is relatively simple and can be easily implemented, and it gives a natural runoff change with lesser data and parameters. Both methods have some uncertainty on the results to some extent. The basically consistent results from the two methods to quantify the responses of streamflow to precipitation variability and human activities were identified. Precipitation variability accounted for $53.66 \%$ and $58.26 \%$ of the decline in annual runoff between the two periods by the two methods, indicating that precipitation variability acted as the main driving force in the runoff decrease, while the role of human activities cannot be neglected neither. The results obtained in this study would provide more evidence and useful reference for water resources planning and management in this region.

\section{Conflicts of Interest}

The authors declare that they have no conflicts of interest.

\section{Acknowledgments}

This study is partially sponsored by the Natural Science Foundation of China (NFSC-50979023) and the Public Welfare Fund of the Ministry of Water Resources (no. 201201026).

\section{References}

[1] T. H. Meek and L. A. Meek, "Increasing inequality is already making shortages worse," Nature, vol. 459, no. 7243, p. 31, 2009.

[2] Z. Zhang, X. Chen, C.-Y. Xu, L. Yuan, B. Yong, and S. Yan, "Evaluating the non-stationary relationship between precipitation and streamflow in nine major basins of China during the past 50 years," Journal of Hydrology, vol. 409, no. 1-2, pp. 81-93, 2011.

[3] C. J. Vörösmarty, P. B. McIntyre, M. O. Gessner et al., "Global threats to human water security and river biodiversity," Nature, vol. 467, no. 7315, pp. 555-561, 2010.

[4] Q. Zhang, V. P. Singh, P. Sun, X. Chen, Z. Zhang, and J. Li, "Precipitation and streamflow changes in China: Changing patterns, causes and implications," Journal of Hydrology, vol. 410, no. 3-4, pp. 204-216, 2011.

[5] P. C. D. Milly, K. A. Dunne, and A. V. Vecchia, "Global pattern of trends in streamflow and water availability in a changing climate," Nature, vol. 438, no. 7066, pp. 347-350, 2005.
[6] O. I. Abdul Aziz and D. H. Burn, "Trends and variability in the hydrological regime of the Mackenzie River Basin," Journal of Hydrology, vol. 319, no. 1-4, pp. 282-294, 2006.

[7] M. Saifullah, Z. Li, Q. Li, M. Zaman, and S. Hashim, "Quantitative estimation of the impact of precipitation and land surface change on hydrological processes through statistical modeling," Advances in Meteorology, vol. 2016, Article ID 6130179, 2016.

[8] X. Chen, D. Naresh, L. Upmanu et al., “China’s water sustainability in the 21st century: a climate-informed water risk assessment covering multi-sector water demands," Hydrology and Earth System Sciences, vol. 18, no. 5, pp. 1653-1662, 2014.

[9] J.-Y. Zhang, S.-L. Zhang, J.-X. Wang, and Y. Li, "Study on runoff trends of the six larger basins in China over the past 50 years," Shuikexue Jinzhan/Advances in Water Science, vol. 18, no. 2, pp. 230-234, 2007.

[10] S. Piao, P. Ciais, Y. Huang et al., "The impacts of climate change on water resources and agriculture in China," Nature, vol. 467, no. 7311, pp. 43-51, 2010.

[11] E. Kahya and S. Kalayc1, "Trend analysis of streamflow in Turkey," Journal of Hydrology, vol. 289, pp. 128-144, 2004.

[12] M. D. Tomer and K. E. Schilling, "A simple approach to distinguish land-use and climate-change effects on watershed hydrology," Journal of Hydrology, vol. 376, no. 1-2, pp. 24-33, 2009.

[13] X. Liu, X. Dai, Y. Zhong, J. Li, and P. Wang, "Analysis of changes in the relationship between precipitation and streamflow in the Yiluo River, China," Theoretical and Applied Climatology, vol. 114, no. 1-2, pp. 183-191, 2013.

[14] Y. Zhang, J. Xia, T. Liang, and Q. Shao, "Impact of water projects on river flow regimes and water quality in Huai River Basin," Water Resources Management, vol. 24, no. 5, pp. 889-908, 2010.

[15] N. Fohrer, S. Haverkamp, and H.-G. Frede, "Assessment of the effects of land use patterns on hydrologic landscape functions: development of sustainable land use concepts for low mountain range areas," Hydrological Processes, vol. 19, no. 3, pp. 659-672, 2005.

[16] N. Zégre, A. E. Skaugset, N. A. Som, J. J. McDonnell, and L. M. Ganio, "In lieu of the paired catchment approach: hydrologic model change detection at the catchment scale," Water Resources Research, vol. 46, no. 11, Article ID W11544, 2010.

[17] F. Zhao, L. Zhang, Z. Xu, and D. F. Scott, "Evaluation of methods for estimating the effects of vegetation change and climate variability on streamflow," Water Resources Research, vol. 46, no. 3, Article ID W03505, 2010.

[18] W. Choi, P. Rasmussen, A. Moore, and S. Kim, "Simulating streamflow response to climate scenarios in central Canada using a simple statistical downscaling method," Climate Research, vol. 40, pp. 89-102, 2009.

[19] G. J. Zhao, P. Tian, X. M. Mu, J. Y. Jiao, F. Wang, and P. Gao, "Quantifying the impact of climate variability and human activities on streamflow in the middle reaches of the Yellow River basin, China," Journal of Hydrology, vol. 519, pp. 387-398, 2014.

[20] F. Chiew and T. McMahon, "Application of the daily rainfallrunoff model MODHYDROLOG to 28 Australian catchments," Journal of Hydrology, vol. 153, no. 1-4, pp. 383-416, 1994.

[21] X. Wei and M. Zhang, "Quantifying streamflow change caused by forest disturbance at a large spatial scale: a single watershed study," Water Resources Research, vol. 46, no. 12, Article ID W12525, 2010. 
[22] W. G. Wang, Q. X. Shao, T. Yang et al., "Quantitative assessment of the impact of climate variability and human activities on runoff changes: a case study in four catchments of the Haihe River basin, China," Hydrological Processes, vol. 27, no. 8, pp. 1158-1174, 2013.

[23] Z. Huo, S. Feng, S. Kang, W. Li, and S. Chen, "Effect of climate changes and water-related human activities on annual stream flows of the Shiyang river basin in arid north-west China," Hydrological Processes, vol. 22, no. 16, pp. 3155-3167, 2008.

[24] S. R. Zhang and X. X. Lu, "Hydrological responses to precipitation variation and diverse human activities in a mountainous tributary of the lower Xijiang, China," Catena, vol. 77, no. 2, pp. 130-142, 2009.

[25] J. C. I. Dooge, M. Bruen, and B. Parmentier, "A simple model for estimating the sensitivity of runoff to long-term changes in precipitation without a change in vegetation," Advances in Water Resources, vol. 23, no. 2, pp. 153-163, 1999.

[26] P. C. D. Milly and K. A. Dunne, "Macroscale water fluxes 2. Water and energy supply control of their interannual variability," Water Resources Research, vol. 38, no. 10, pp. 24.1-24.9, 2002.

[27] R. N. Jones, F. H. S. Chiew, W. C. Boughton, and L. Zhang, "Estimating the sensitivity of mean annual runoff to climate change using selected hydrological models," Advances in Water Resources, vol. 29, no. 10, pp. 1419-1429, 2006.

[28] X. Zhang, L. Zhang, J. Zhao, P. Rustomji, and P. Hairsine, "Responses of streamflow to changes in climate and land use/cover in the Loess Plateau, China," Water Resources Research, vol. 45, no. 7, Article ID W00A07, 2009.

[29] Q. Liu, Z. Yang, B. Cui, and T. Sun, “Temporal trends of hydroclimatic variables and runoff response to climatic variability and vegetation changes in the Yiluo River basin, China," Hydrological Processes, vol. 23, no. 21, pp. 3030-3039, 2009.

[30] J. C. Schaake and P. Waggoner, "From climate to flow," Climate change and US water resources, pp. 177-206, 1990.

[31] H. Zheng, L. Zhang, R. Zhu, C. Liu, Y. Sato, and Y. Fukushima, "Responses of streamflow to climate and land surface change in the headwaters of the Yellow River Basin," Water Resources Research, vol. 45, no. 7, Article ID W00A19, 2009.

[32] H. B. Mann, "Nonparametric tests against trend," Econometrica, vol. 13, pp. 245-259, 1945.

[33] C. F. Kossack, "Recent Publications: Rank Correlation Methods," American Mathematical Monthly, vol. 57, no. 6, pp. 425426, 1950.

[34] R. Sneyers, Sur lanalysestatistique des s@riesd'observations, Secrétariat de l'Organisation Météorologique Mondiale, 1975.

[35] D. R. Helsel and R. M. Hirsch, "Preface," in Statistical Methods in Water Resources, vol. 49 of Studies in Environmental Science, pp. xv-xvi, Elsevier, 1992.

[36] D. P. Lettenmaier, E. F. Wood, and J. R. Wallis, "Hydroclimatological trends in the continental United States, 1948-88," Journal of Climate, vol. 7, no. 4, pp. 586-607, 1994.

[37] D. H. Burn and M. A. H. Elnur, "Detection of hydrologic trends and variability," Journal of Hydrology, vol. 255, no. 1-4, pp. 107122, 2002.

[38] S. Yue, P. Pilon, and B. Phinney, "Canadian streamflow trend detection: Impacts of serial and cross-correlation," Hydrological Sciences Journal, vol. 48, no. 1, pp. 51-64, 2003.

[39] Z. Zhang, C.-Y. Xu, M. E.-H. El-Tahir, J. Cao, and V. P. Singh, "Spatial and temporal variation of precipitation in Sudan and their possible causes during 1948-2005," Stochastic Environmental Research and Risk Assessment, vol. 26, no. 3, pp. 429-441, 2012.
[40] J. M. Moraes, G. Q. Pellegrino, M. V. Ballester, L. A. Martinelli, R. L. Victoria, and A. V. Krusche, "Trends in hydrological parameters of a southern Brazilian watershed and its relation to human induced changes," Water Resources Management, vol. 12, no. 4, pp. 295-311, 1998.

[41] F.-W. Gerstengarbe and P. C. Werner, "Estimation of the beginning and end of recurrent events within a climate regime," Climate Research, vol. 11, no. 2, pp. 97-107, 1999.

[42] A. Sankarasubramanian, R. M. Vogel, and J. F. Limbrunner, "Climate elasticity of streamflow in the United States," Water Resources Research, vol. 37, no. 6, pp. 1771-1781, 2001.

[43] J. K. Searcy and C. H. Hardison, 1960.

[44] D. Legesse, C. Vallet-Coulomb, and F. Gasse, "Hydrological response of a catchment to climate and land use changes in Tropical Africa: case study south central Ethiopia," Journal of Hydrology, vol. 275, no. 1-2, pp. 67-85, 2003.

[45] F. H. S. Chiew, "Estimation of rainfall elasticity of streamflow in Australia," Hydrological Sciences Journal, vol. 51, no. 4, pp. 613$625,2006$. 

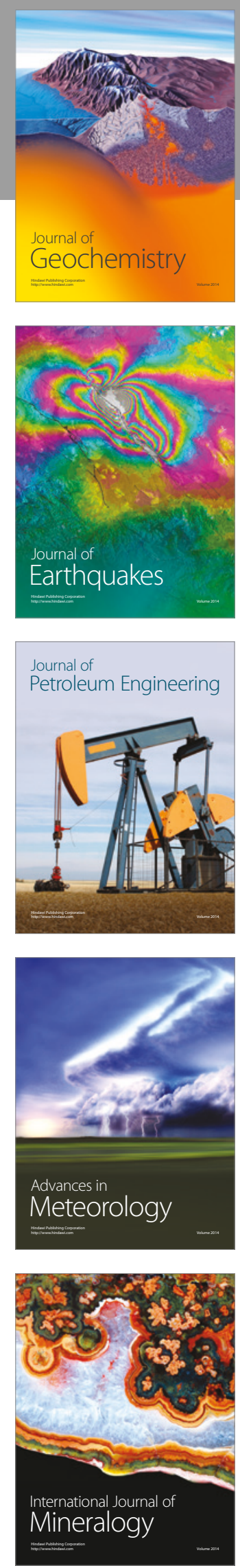
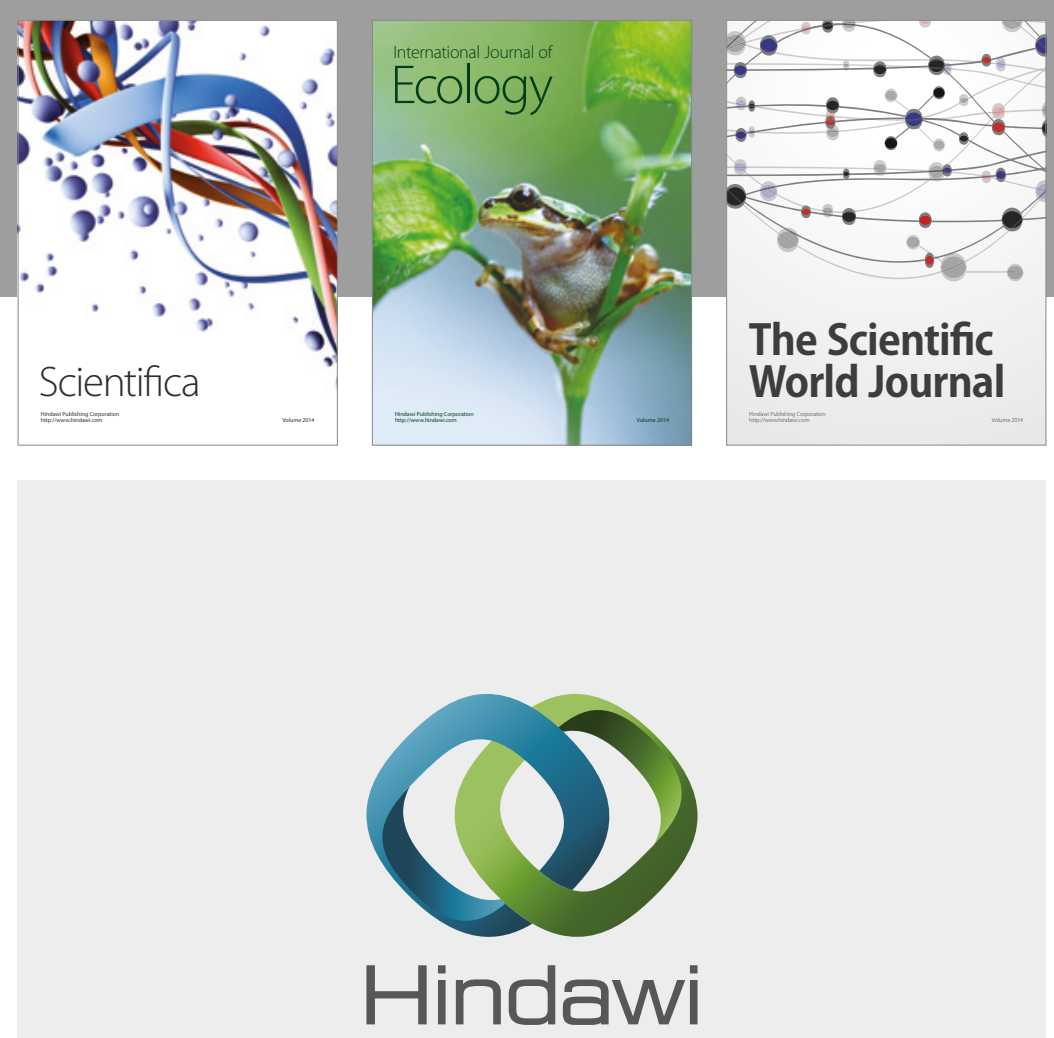

Submit your manuscripts at

https://www.hindawi.com
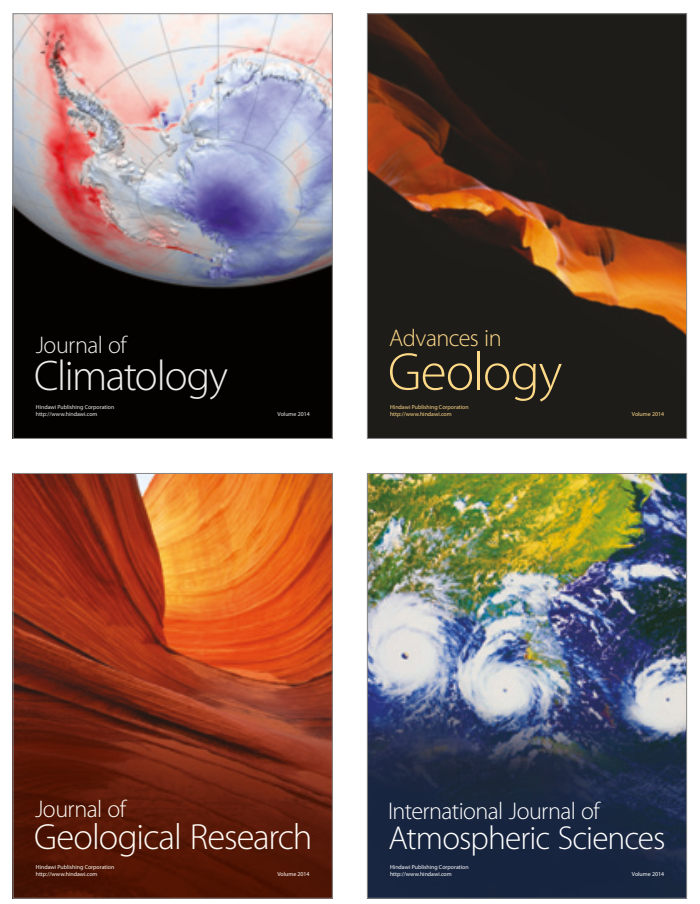

The Scientific

World Journal
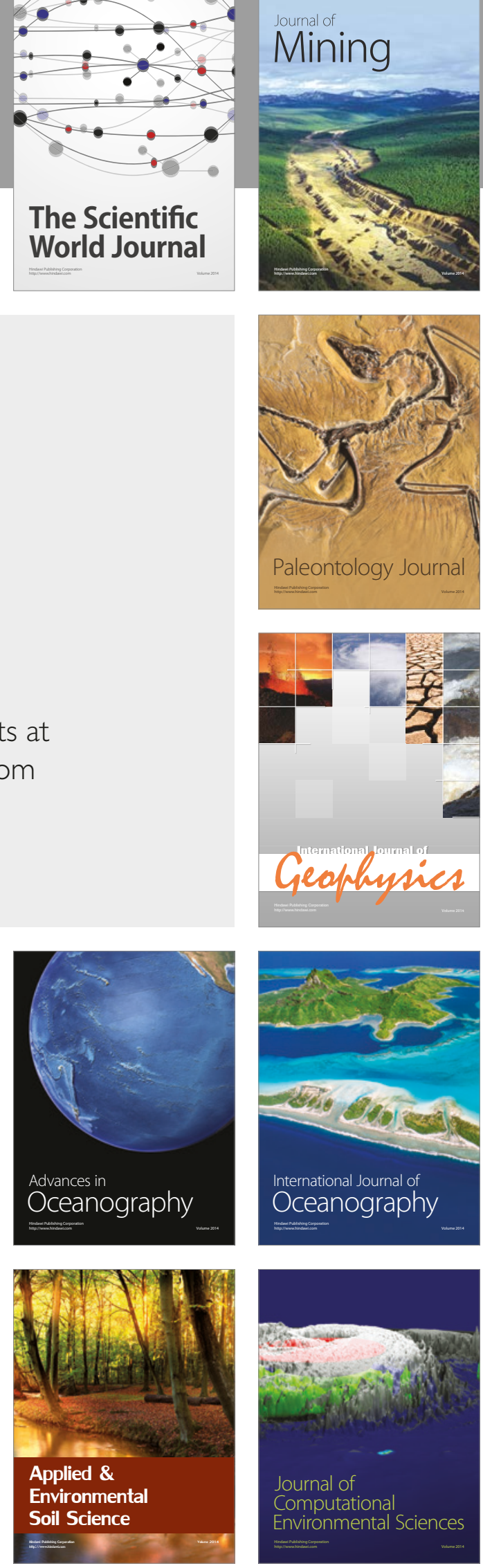